\title{
O ASSOCIATIVISMO COMO INSTRUMENTO DE FORTALECIMENTO E EMPODERAMENTO DAS ORGANIZAÇÕES FEMININAS DO MUNICÍPIO DE SANTALUZ-BA
}

\author{
$\underline{\text { Maria Carolina de Oliveira Silva }}{ }^{1}$; Acácia Batista Dias ${ }^{2}$; Ildes Ferreira de Oliveira ${ }^{3}$ \\ 1. Bolsista PIBIC/CNPq, Graduanda em Psicologia, Universidade Estadual de Feira de Santana, e-mail: \\ caroliina_002@hotmail.com \\ 2. Orientador, Departamento de Ciências Humanas e Filosofia, Universidade Estadual de Feira de Santana, e-mail: \\ acaciabatista02@gmail.com \\ 3. Coordenador do Projeto Ser Tão Forte: Desenvolvimento Territorial Sustentável, Departamento de Ciências \\ Humanas e Filosofia, Universidade Estadual de Feira de Santana, e-mail: ildesferreira@ gmail.com
}

PALAVRAS-CHAVE: Mulher; Associativismo; Empoderamento.

\section{INTRODUÇÃO}

Esta pesquisa está vinculada ao projeto "SER TÃO FORTE: Desenvolvimento Territorial Sustentável“ (CNPq/MDA/SPM-PR No 11/2014 - Núcleos de Extensão em Desenvolvimento Territorial (NEDET). O tema investigado refere-se às contribuições da atuação da Associação do Movimento de Mulheres Trabalhadoras Rurais de Santaluz (AMMTRAFAS), por meio da organização de grupos de produção para o trabalho, da participação em políticas públicas e do estabelecimento de redes de colaboração para um processo de organização, fortalecimento e empoderamento das mulheres no município de Santaluz.

O referido município está localizado no Território do Sisal possui uma área de $1.563,291 \mathrm{~km}^{2}$ e uma população de 33.838 habitantes, dos quais 20.075 residem nas áreas urbanas, enquanto que 13.043 vivem na área rural. Contudo, os índices apontam que no ano de 2016 a população atingiu a marca de 38.219 habitantes. (IBGE, 2010).

As agricultoras do Território do Sisal vivenciam condições de vida destacadas pela miséria, pelo trabalho duro e mal ou não remunerado, o que se constitui em uma motivação para o estabelecimento de organizações coletivas (FIRMO, 2010).

Diante dessas condições de desigualdades, os movimentos e organizações sociais passaram a ser estratégias de luta na busca pela autonomia. Nesta perspectiva, a região do Sisal é também caracterizada pela existência de organizações coletivas, dentre essas, AMMTRAFAS. (SANTO et al, 2006).

A AMMTRAFAS é uma associação direcionada às mulheres que tem sua origem associada ao Movimento de Mulheres Trabalhadoras Rurais (MMTR) de Santaluz, que possuem como principais propósitos: a produção de trabalho e renda para as agricultoras e o reconhecimento do trabalho das mulheres rurais (PIRES, 2016). A atuação da AMMTRAFAS se dá junto a grupos de produção com o propósito de favorecer a inclusão social e autonomia dessas mulheres.

Assim, a pesquisa desenvolvida teve como objetivo analisar a atuação da AMMTRAFAS e sua contribuição no processo de organização, fortalecimento e empoderamento das mulheres no município de Santaluz, expressas através dos discursos das entrevistadas, demonstrando a conscientização das mesmas sobre a situação desfavorável na qual estão imersas e a forma que as associações propiciam o acesso às políticas públicas e uma consequente busca da autonomia pessoal e financeira. 


\section{MATERIAL E MÉTODOS}

O percurso metodológico iniciou-se por uma busca de referências bibliográficas a respeito do tema, leitura, análise e sistematização dos resultados. A descrição do município foi realizada através de dados secundários de fontes como Instituto Brasileiro de Geografia e Estatística (IBGE).

Realizou-se o contato com representantes da AMMTRAFAS, apresentou-se a proposta de pesquisa e em seguida foram feitas as entrevistas semiestruturadas com as mesmas, por meio das quais foram obtidas informações históricas, benefícios proporcionados pela associação, políticas públicas acessadas pelas representantes, dificuldades enfrentadas, instituições parceiras da associação. Além disso, visando investigar a relação de cooperação da AMMTRAFAS com outras entidades, foi realizada uma entrevista com um ex-presidente da ASCOOB Itapicuru. Ao final, as entrevistas foram transcritas, analisadas e sistematizadas.

\section{RESULTADOS E/OU DISCUSSÃO}

Foram realizadas quatro entrevistas semiestruturadas, uma com a presidente da AMMTRAFAS, duas com representantes, que atualmente ocupam na associação o cargo de comerciante, e uma entrevista com um ex-presidente da ASCOOB Itapicuru.

Em geral, a inserção das mulheres na organização ocorre por motivos financeiros, visto que a associação possibilita a geração de trabalho e renda, criando meios que contribuam para tal fim, como por exemplo, a inserção no mercado por meio do ingresso na loja Maria Bonita, conforme demonstrado a seguir: Hoje eu já estou aqui fazendo um trabalho pra substituir J e ficar como colaboradora da loja. Mais uma porta se abriu pra mim, porque eu nunca tive a oportunidade de ter um trabalho (M. L, 29 anos, comerciante da AMMTRAFAS)

Além de oportunizar a geração de trabalho e renda, algumas mulheres também relatam como benefício proporcionado pela instituição, a ampliação do conhecimento, maior independência, empoderamento, maior acesso às políticas públicas; especificamente ao Programa de Aquisição Alimentar (PAA) e o Programa Nacional de Alimentação Escolar (PNAE), maior autoestima e identidade de grupo, sendo motivadas a se inserirem em espaços que nunca pensaram em estar (PIRES, 2016), como relata uma das entrevistadas: Eu comecei a construir minha identidade mesmo, de dizer eu sou isso, eu nasci pra ficar aqui, pra fazer a diferença no meu povoado e dá valor entendeu?(...) Conheci muita coisa boa, fiz intercâmbio pra Argentina através da AMMTRAFAS (...). Aí hoje eu sou formada como técnica administrativa também. (...) dou valor de onde sou, dou valor de onde eu vim. (J.C, 28 anos, ensino médio completo, comerciante da AMMTRAFAS)

Além disso, a fim de alcançar seus objetivos, a AMMTRAFAS estabelece parcerias que favorecem o intercâmbio de conhecimentos e informações, assim como contribui na produção e comercialização. Dentre essas, destacam-se a Associação das Cooperativas de Apoio a Economia Familiar (ASCOOB) Itapicuru, a Cooperativa de Beneficiamento e Comercialização (COOBENCOL), a Central de Apoio as Associações (CEAIC), o Movimento de Organização Comunitária (MOC), a Cooperativa Rede de 
Produtoras da Bahia (COOPEREDE) e o Sindicato dos Trabalhadores e Trabalhadoras Rurais (STR) do município de Santaluz. Como é apresentado no discurso a seguir: As cooperativas que estão vinculadas é a ASCOOB, que a gente tem uma parceria muito boa e a COOBENCOL. Nós temos também a cooperativa que é a COOBENCOL. (...). Aí a gente tem o CEAIC, que é a Central das Associações do município, temos o Sindicato. (L.S, 28 anos, presidente da AMMTRAFAS)

Apesar de todos os benefícios proporcionados, há ainda muitas limitações e problemas que se configuram como desafios para a associação, principalmente porque muitas das ações não estão em concordância com os interesses de outros agentes sociais da escala municipal, estadual e/ou federal.

Bonetti (2007) afirma que as condutas e as ações da sociedade interferem na composição das políticas públicas. Atividades referentes as diversas dimensões da sociedade tais como, a sistematização da produção e as relações de poder, sejam nacionais ou universais induzem os interesses e os artifícios econômicos e sociais das categorias que propõem as políticas públicas em uma sociedade capitalista.

Assim, as representantes da instituição trazem a falta de recursos financeiros e a falta de apoio do poder público como principal entrave no alcance das propostas, como nos relata L.S (28 anos, presidente da AMMTRAFAS): Mas dificuldade tem a questão do poder público que a gente não tem aqui e nós temos dificuldade na questão financeira (...).

Além disso, denunciam a importância de maior apoio do poder público municipal, a fim de proporcionar mais oportunidades de geração de trabalho e renda para as mulheres associadas. Com isso, torna-se essencial que toda a sociedade esteja atenta e participativa, principalmente no processo de elaboração e avaliação de políticas públicas, já que se trata de uma intervenção social que atinge a todos. Além disso, é fundamental a ampliação de espaços que contribuam na publicização das desigualdades de gênero existentes e para um processo de conscientização coletiva da sociedade em geral.

\section{CONSIDERAÇÕES FINAIS}

Durante a pesquisa foi perceptível que a atuação da AMMTRAFAS tem proporcionado transformações na vida das mulheres tais como, a obtenção de renda por meio da comercialização de produtos, uma ampliação do conhecimento, maior acesso ás políticas públicas, maior independência, empoderamento, autoestima, identidade de grupo, maior acesso á políticas públicas, formação política e consequentemente maior espaço de representação política.

No entanto, apesar de alguns avanços a associação ainda encontra limitações tais como a falta de apoio do poder público que repercute na falta de recursos financeiros disponíveis para as atividades e as dificuldades de muitas associadas em se livrar das amarras da hegemonia masculina e se reconhecer como sujeitos responsáveis por suas escolhas. 
Assim, torna-se necessário uma maior atenção do poder público através da oferta de mais oportunidades para essas mulheres e uma maior participação de todos, principalmente das mulheres nas atividades de elaboração e execução das políticas públicas, bem como a criação de espaços de discussão coletiva, que contribuam na publicização das desigualdades de gênero existentes, produzindo discursos que vão contra idéias opressivas hegemônicas sobre as mulheres, favorecendo uma conscientização de todos diante das desigualdades, incentivando uma maior independência das mulheres e consequentemente maior reconhecimento das mesmas, como sujeitos de direitos.

\section{REFERÊNCIAS}

BONETI , L. W.2007. Políticas Públicas por dentro. 2 ed,Ijuí

Instituto Brasileiro de Geografia e Estatística (IBGE), IBGE CIDADES @, 2010. [online]: https://cidades.ibge.gov.br/brasil/pi/santa-luz/panorama

LIMA, P.R.L. 2004. Análise teórica e experimental de compósitos reforçados com fibras de sisal. Universidade Federal do Rio de Janeiro, Tese

FIRMO, C.F.2010. Desenvolvimento Territorial Sustentável e Gênero: o caso do território Sisaleiro da Bahia. Universidade Federal de Minas Gerais, Monografia (Especialização).

PIRES, S.M.2016. A atuação da Associação de Mulheres Trabalhadoras Rurais no contexto das políticas de segurança alimentar e a constituição de novas territorialidades em Santa Luz - Bahia. Universidade Estadual de Feira de Santana, Dissertação (Mestrado em Planejamento Territorial).

SANTO, J. E; SILVA, J.S.; VELLOSO, T.R. 2006. Cooperjovens: uma Experiência Juvenil de Cooperativismo Solidário na Região Sisaleira da Bahia. Imaginário. 12(12):195-204. 